\title{
Development of a Mathematical Procedure for Controlling Air Flow Rate in Tea Withering
}

\author{
W.M.S. Weerawardena ${ }^{1}$, K.S.P. Amarathunga ${ }^{2}$ and W.S. Botheju ${ }^{1}$ \\ Postgraduate Institute of Agriculture \\ University of Peradeniya \\ Sri Lanka
}

\begin{abstract}
A control system was developed for optimizing the electrical energy consumption while preserving the required quality of withered tea leaves. The electrical energy saving was achieved by controlling the speed of the fan through a variable speed drive (VSD) and controlling the hot and ambient air delivering into the trough. The fan speed was determined based on the theoretical mass flow rate requirement of air calculated by the mathematical model developed for withering, while calculating the thermodynamic properties of withering air and the moisture content of tea leaves in real time. A single board computer, Raspberry pi 3 model $B$, was used as the controller to run the mathematical model and the software programme to control the VSD for controlling the mass flow rate of air delivered, the air temperature and the relative humidity. Finally, the electrical energy consumption of the fan and the quality parameters of tea were measured through experiments and compared in the withering process with or without control system. The specific energy consumption of withering was in the range of 0.17 to $0.18 \mathrm{kWh} / \mathrm{kg}$ of made tea with the control system and it was 0.27 to $0.35 \mathrm{kWh} / \mathrm{kg}$ of made tea without control system. The electrical energy consumption was $36 \mathrm{kWh}$ to $39 \mathrm{kWh}$ with the control system and it was in the range of $55 \mathrm{kWh}$ to $67 \mathrm{kWh}$ in without control system. Therefore, 39\% of electrical energy was saved by introducing the control system compared to the withering process without control system.
\end{abstract}

Keywords: Control system, mathematical model, raspberry Pi, tea withering

\section{INTRODUCTION}

Black tea production process consists of five major unit operations such as withering, rolling and roll breaking, fermentation, drying, grading and packing. Withering is the first step in the manufacture of black tea by orthodox method (Eden, 1958; Keegel, 1958; Harler, 1963). The main objective of withering is to reduce moisture in tea leaves to render its physical condition suitable for the subsequent rolling stage (Millin, 1987). The initial moisture content (MC) of tea leaves $72-83 \%$ in wet basis $(\mathrm{wb})$ is reduced to $55-60 \%$ by passing air through a bed of tea leaves in orthodox or orthodox rotor-vane type of tea processing.

Out of five major unit operations, withering consumes the highest amount of electrical energy (Haskoning, 1989) and considerable amount of thermal energy. It consumes about $49 \%$ of total

\footnotetext{
${ }^{1}$ Tea Research Institute of Sri Lanka, Thalawakelle, Sri Lanka

2 Department of Agricultural Engineering, Faulty of Agriculture, University of Peradeniya, Sri Lanka

* Corresponding author: samanthikaw@yahoo.com
}

This is an open-access article distributed under the terms of the Creative Commons Attribution License, which permits unrestricted use, distribution, and reproduction in any medium, provided the original author and source are credited. 
electrical energy in the Up-country tea factories and $61 \%$ of total electrical energy in the Lowcountry tea factories (De Silva, 1994). The thermal and electrical energy consumption in withering can be minimized by adoption of more efficient process control systems. The relative humidity, airflow rate and the temperature of the withering air are the most important parameters of the withering process. The temperature of the withering air is needed to control below $32^{\circ} \mathrm{C}\left(90^{\circ} \mathrm{F}\right)$ to avoid discoloration of withered leaves. Hot air and ambient air dampers in the mixing chamber are adjusted manually to control air temperature and the rate of air flow. If the withering fan is coupled with variable speed drive, speed of the fan can be controlled manually to achieve the recommended withering parameters.

In year 2002, variable speed drives (VSDs) were introduced to the tea industry to minimise the electrical energy consumption. A study revealed that the $40 \%$ of electrical energy could be saved by proper control of airflow in the withering process with the variable speed drive, without affecting the quality of tea (Daranagama et al., 2002). Different types of VSDs with programmable facility have been installed in tea factories in order to reduce electrical energy consumption. However, the tea factories have not achieved the real benefits of VSDs because it could not be adjusted automatically according to the required air flow rates. At present, most of the industries are intended to use automated controllers to monitor and control the process parameters. Therefore, it is identified that the controlling of withering process parameters such as withering temperature, relative humidity and the air flow rate are essential and important to save electrical energy. In this study, an attempt was made to develop a mathematically controlled process to automate the trough withering process of tea to achieve the electrical energy saving while maintaining the quality.

\section{METHODOLOGY}

A control system was developed for optimizing the electrical energy consumption in tea withering. The electrical energy was achieved by controlling the mass flow rate of withering air. In this study, the temperature (T1, T2) and the relative humidity (RH1, RH2) obtained from the sensors were fed as initial conditions to the mathematical model to calculate thermodynamic properties of withering air and the moisture content of tea leaves in real time for determining the mass flow requirement of air. A mathematical model developed (Botheju et al., 2010) was used for calculating mass flow rate of air during the withering. Mass flow rate was adjusted by the controlling fan speed and it was regulated by the variable speed drive (VSD) through the micro-processor based control system. Experiments were conducted in assessing the electrical energy saving and the quality attributes of withered tea leaves. The flow chart of the operational procedure of the control system is shown in Figure 1.

The experiment was carried at St. Coombs Estate tea factory, belongs to the Tea Research Institute, Talawakelle. Green leaves plucked from St. Coombs estate were used in the withering experiments. The experimental withering trough selected in this study has a length of $18.29 \mathrm{~m}$ and a width of $1.83 \mathrm{~m}$ and fixed with a withering fan having $1.22 \mathrm{~m}$ diameter with a capacity of 7.5 HP motor. 


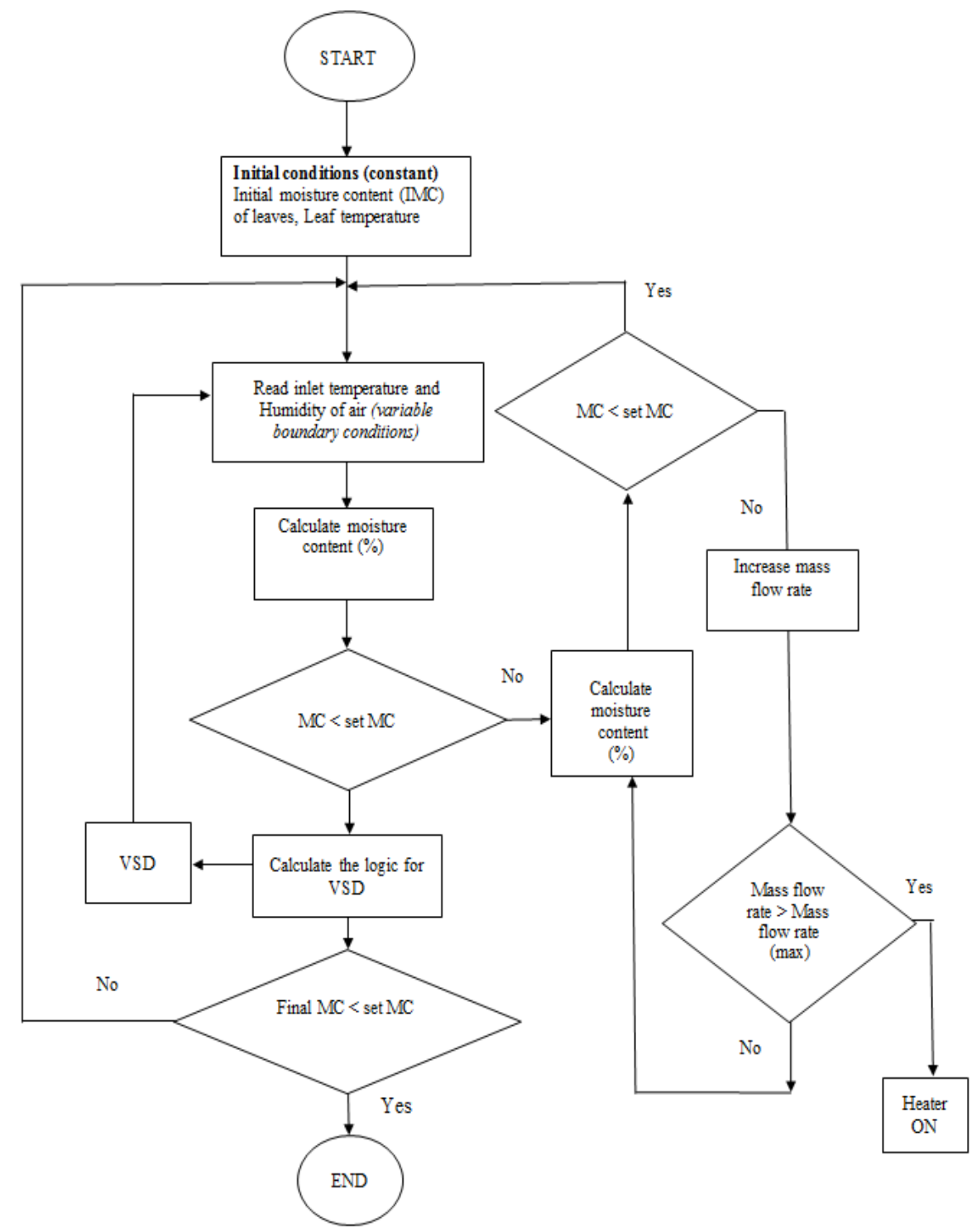

Figure 1. Flow chart of operational procedure.

The Figure 2 shows the experimental set up of the control system developed for optimizing the electrical energy consumption in tea withering. In this system VSD was used to regulate the airflow through the fan motor. Hot air ducting arrangement consisted of heating elements with a capacity of $27 \mathrm{~kW}$. The temperature and $\mathrm{RH}$ sensors were placed close to the front and the rear ends in the withering trough chamber to measure temperature and relative humidity of air in the air plenum below the leaves. Using these temperature and $\mathrm{RH}$ data, real time moisture content, psychometric properties of air were calculated by the mathematical model. The model calculated real time moisture contents were taken as the controller output while predicting the moisture content in the next ten minutes of withering, assuming the air conditions are not 
changing. In this study standard linear curve of moisture contents vs. time was taken as the set points of the control system. The linear standard curve was obtained by setting initial moisture content at time zero and final required moisture content at the desired set time (e.g. 12 hours). Then the difference between moisture content of the withered leaves calculated by the model and the standard withering curve for an extrapolated time (ten minutes) were calculated. Depending on the error, calculated (deference between set point and the predicted moisture content), by the programme the mass flow rate was adjusted iteratively until the error was minimal. The final goal of achieving the electrical energy optimization was based on supplying the optimum air flow. The program then provided the necessary signal to the VSD and the heating device in order to adjust the mass flow rate delivered by withering fan as well as the temperature of air.

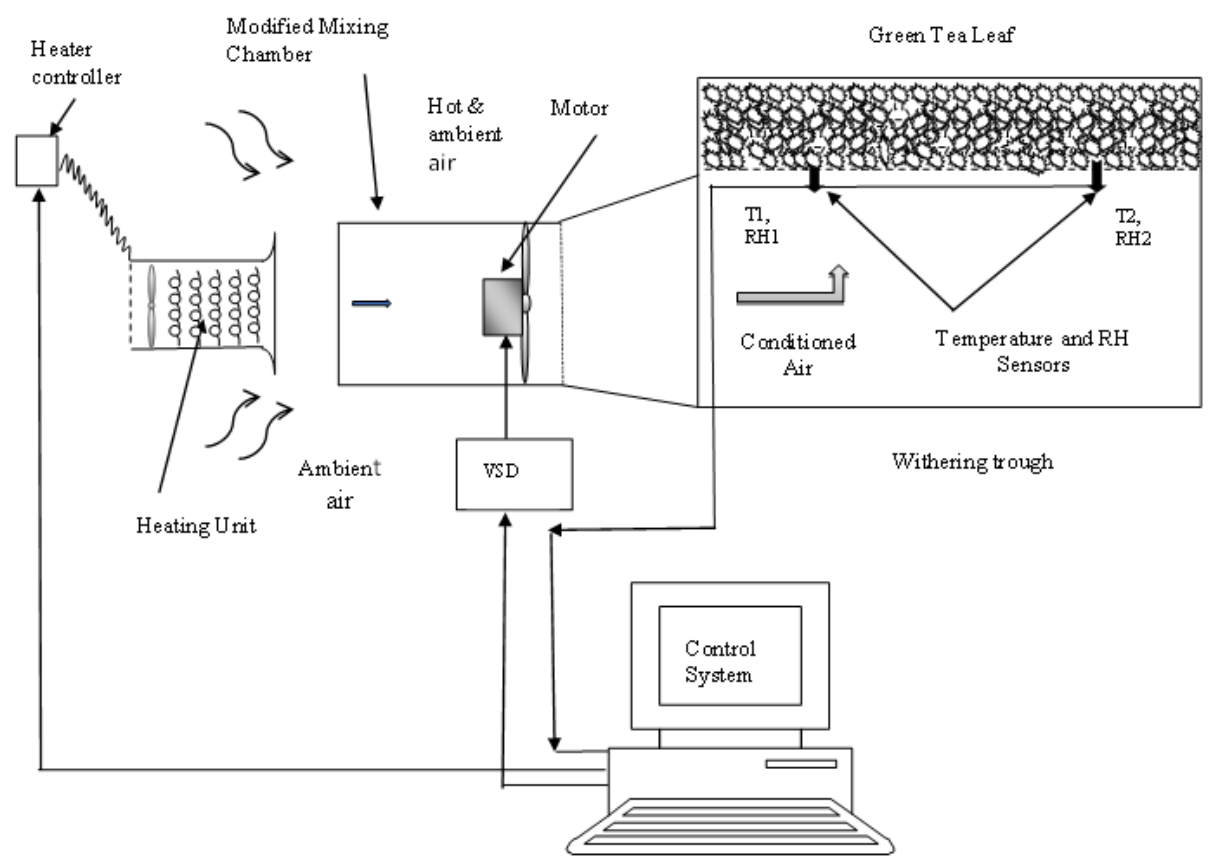

Figure 2. Experimental withering set up.

\section{Hardware for applying the model for trough withering}

A programme with the mathematical model, written in 'python' language, was run on the single board computer to operate the heater and the VSD driven withering trough fan. The three phase variable speed drive (ATV 312HU15N4) was used to vary the speed of the fan and change the mass flow rate of the inlet air to the withering trough. The temperature sensors (LM35, Texas instruments) and the humidity sensors (Honey well, HIH4000 series, USA) were used to measure the temperature and the humidity of the inlet air of the plenum chamber in the experimental trough.

Arduino-nano (AT mega 328) was used to control the inlet air temperature of the withering air. The controller, Raspberry Pi 3 model B was serially connected with the Arduino-nano 
board to get the required set temperature of the inlet air. The programme was written in $\mathrm{C}$ language for the Arduino-nano board. The required temperature of the heater was calculated by the programme run in the Raspberry Pi 3 model B was sent to the Arduino-nano board as pulse width modulated signal.

According to the developed mathematical model (Botheju et al., 2010) the final moisture contents was directly depends on the incremental time. The incremental time $(\Delta t)$ is the time required to occur heat and mass transfer process of inlet air at different layers of the withering bed of tea leaves. Several tests with different $\Delta t$ were done to select the best fit $\Delta t$ of the mathematical model for withering tea, Finally, two tests were conducted with $(\Delta t)$ as 5.7 and $5.9 \mathrm{~s}$ to select the best fit $(\Delta t)$ and achieving the lowest standard error of estimation. The withered leaves moisture contents and the model simulated moisture contents for the incremental time $(\Delta t) 5.7$ and 5.9 s were obtained and compared.

\section{Validation of the control system for energy saving and quality of tea withering}

Three test runs were studied in detail for validating the model for energy saving and quality attributes with the control system and without the control system. The tea leaves $(900 \mathrm{~kg})$ were plucked and loaded with the recommended loading rate at the experimental withering trough. The trough fan was switched on and the tea leaves were loosened properly. The initial moisture content of fresh leaves determined by the microwave oven method (Mohamed et al., 2003) and the leaf temperature were given as the initial conditions to the mathematical model. Then the withering process was carried out with the micro-processor based control system. The inlet air temperature, relative humidity, real time moisture content and the frequency of the VSD were recorded by the control system during the withering period. The power consumption of the withering trough fan was measured using a power analyser (Fluke, model 434 series ii, serial No. 34563001, Romania) throughout the withering period. The withering experiments, without the control system, were carried out with the same quantity of green leaves on the experimental withering trough. The trough fan was switched on and the leaves were loosened properly. The initial moisture and final moisture contents of tea leaves were determined by standard oven method (ISO 1568, 1980) and the electrical power consumption of the fan was measured by the power analyser (Fluke, model 434 series ii, serial No. 34563001, Romania). The initial frequency was kept at $50 \mathrm{~Hz}$ until the turning of leaf and the frequency was varied to $45 \mathrm{~Hz}$ after turning of leaf. After four hour of turning the leaves, the frequency was changed up to $40 \mathrm{~Hz}$ till the end of withering process. The electrical power consumption, measured in withering process without control system, was compared with the electrical power consumption with control system. The quality parameters of tea samples, such as Thearubigins, Theaflavin, total color and the brightness were analysed by Robert and Smith (1963) method. Tea samples were prepared by manufacturing withered leaves with the withering process without control system and the withering process with the control system.

\section{RESULTS AND DISCUSSION}

\section{Modification to the existing mathematical model and the control system.}

Two trials were conducted in the experimental withering trough with the incremental time ( $\Delta t$ ) as 5.7 and 5.9 to investigate the effect of changing the incremental time on the final 
moisture content. The withered leaves moisture content and the model computed moisture content for the incremental time ( $\Delta t) 5.9 \mathrm{~s}$ are presented in the Figure 3. This showed that the model computed moisture contents significantly matched the measured moisture contents.

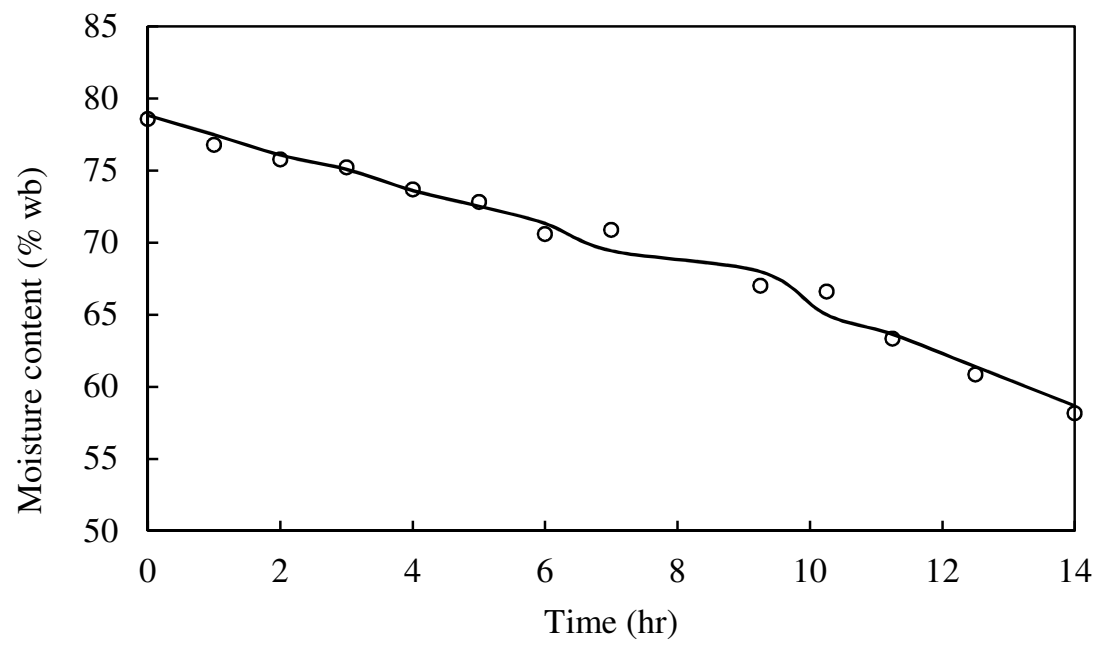

— Model computed moisture content $\quad$ Withered leaves moisture content

Figure 3. The moisture contents of withering leaves and the model computed moisture contents at $\Delta t=5.9 \mathrm{~s}$.

According to the Table 1, standard error of estimation was 4.04 with the incremental time of 5.7 and it was 0.84 for the incremental time $5.9 \mathrm{~s} \%$ wet basis. Therefore, it shows the withered leaves moisture content and the model computed moisture content for the incremental time ( $\Delta t$ ) 5.9 was very close to each other. However, the electrical energy consumption was 38.57 $\mathrm{kW}$ in the incremental time of $5.7 \mathrm{~s}$ and it was $50.34 \mathrm{~kW}$ for the incremental time of $5.9 \mathrm{~s}$.

Table 1. Comparison of differences in moisture content of withering leaves with two incremental times $(\Delta t) 5.7$ and 5.9s.

\begin{tabular}{lccccc}
\hline Experiments & $\begin{array}{c}\text { Initial } \\
\text { MC\% }\end{array}$ & $\begin{array}{r}\text { Final } \\
\text { MC\% }\end{array}$ & $\begin{array}{c}\text { Withering } \\
\text { period (hr) }\end{array}$ & $\begin{array}{c}\text { Energy } \\
(\mathbf{k W})\end{array}$ & $\begin{array}{c}\text { Standard error } \\
\text { of estimation }(\% \\
\text { moisture content } \\
\text { wet basis) }\end{array}$ \\
\hline $\begin{array}{l}\text { Incremental } \\
\text { time } \Delta t 5.7\end{array}$ & 75.2 & 56.6 & $12: 00$ & 38.57 & 4.04 \\
$\begin{array}{l}\text { Incremental } \\
\text { time } \Delta t 5.9\end{array}$ & 78.6 & 58.2 & $14: 00$ & 50.34 & 0.84 \\
\hline
\end{tabular}




\section{Control system for energy saving and quality of tea withering}

Three withering trials were carried out in an experimental withering to validate the developed control system for optimization of electrical energy usage and quality of withering. The initial moisture content of the green leaves of the first trial was $78 \%$ and was having surface moisture due to the rainy weather during plucking. At the start, the fan speed was at a frequency of 44 $\mathrm{Hz}$ and the control system automatically reduced it to $39 \mathrm{~Hz}$ with increase of temperature of the inlet air to the withering trough. However, after few minutes the frequency of the fan was increased again, according to the next set point of the linear standard withering curve. Following the control algorithm (Figure 1) the control system automatically changed the frequency of the supply voltage through the VSD as necessary throughout the withering period.

The measured thermodynamic properties of inlet air, real time moisture content, frequency and the power consumption during the withering period with the control system in the first trial is shown in Figure 4.

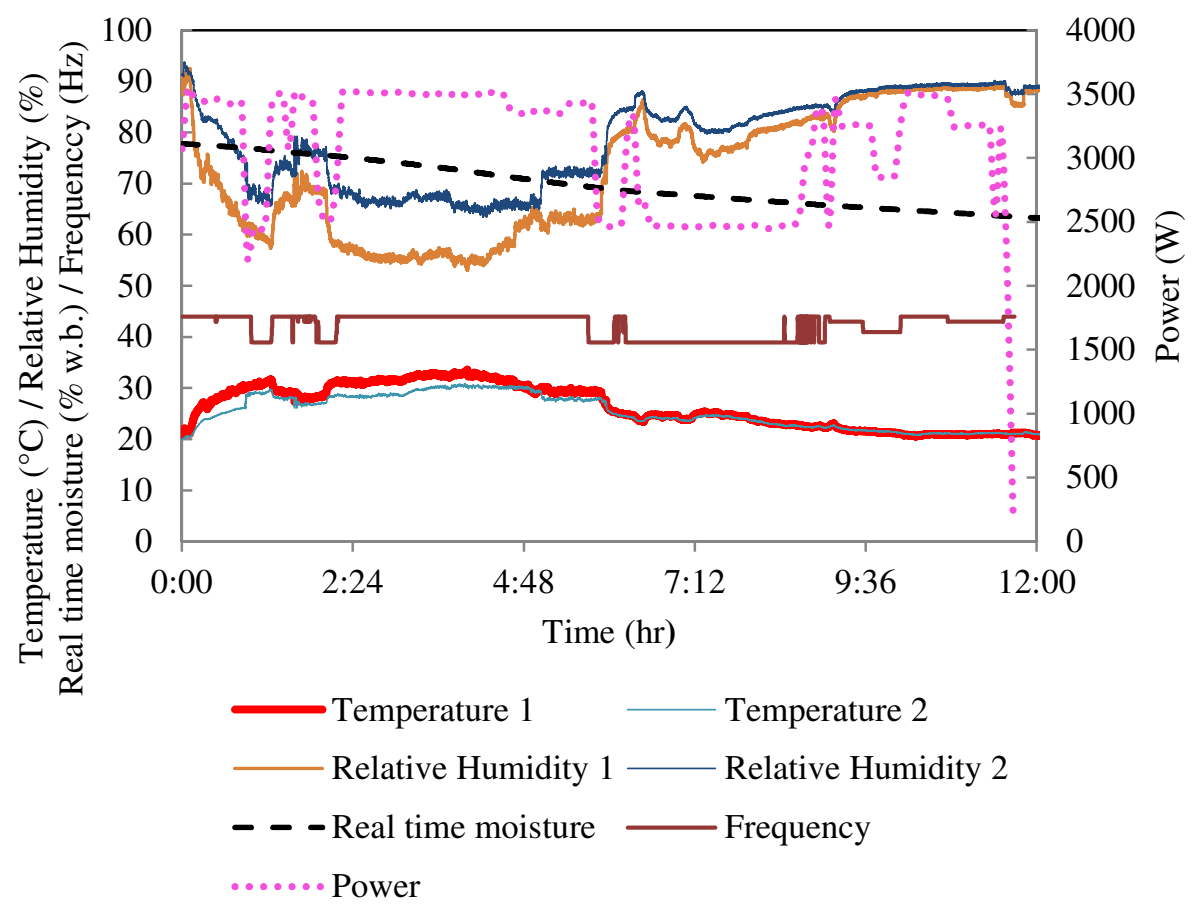

Figure 4. Thermodynamic properties of inlet air, real time moisture content, frequency and the power consumption during the withering period with the control system.

The initial leaf moisture contents of the other two trials were $76.2 \%$ and $75.2 \%$. The frequency of the VSD was varied in the range of 39 to $44 \mathrm{~Hz}$ in these two trials. The power consumption was varied within five minutes in the range of $3000 \mathrm{~W}$ to $3500 \mathrm{~W}$ and $2500 \mathrm{~W}$ to $3000 \mathrm{~W}$ in 
the second and third trials respectively. The temperature of the inlet air does not exceed the $30{ }^{\circ} \mathrm{C}$ and it was maintained always below the recommended temperature of $32{ }^{\circ} \mathrm{C}$ (T.R.I. Advisory circular 2003). The measured power consumptions with time, with the control system in the first trial and the without control system are shown in Figure 5.

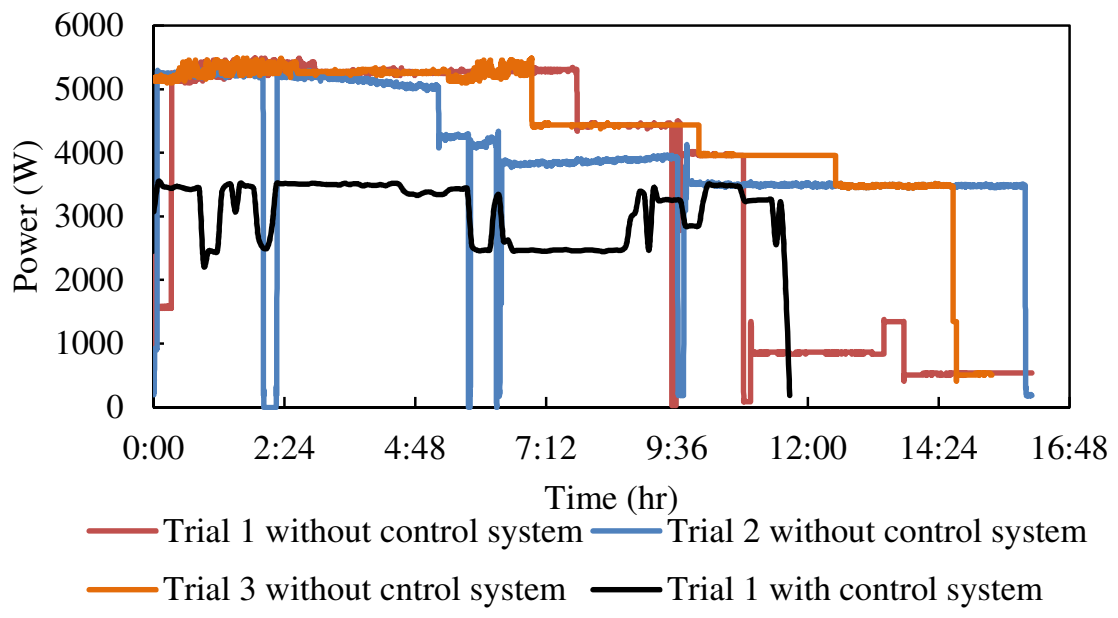

Figure 5. Power consumptions with time, with the control system in the first trial and the without control system.

These three trials were used to compare moisture content of tea leaves computed by the model with the actual moisture contents of withered leaves during withering. The obtained moisture contents of withered leaves and the model computed moisture contents for the second trial are presented in the Figure 6.

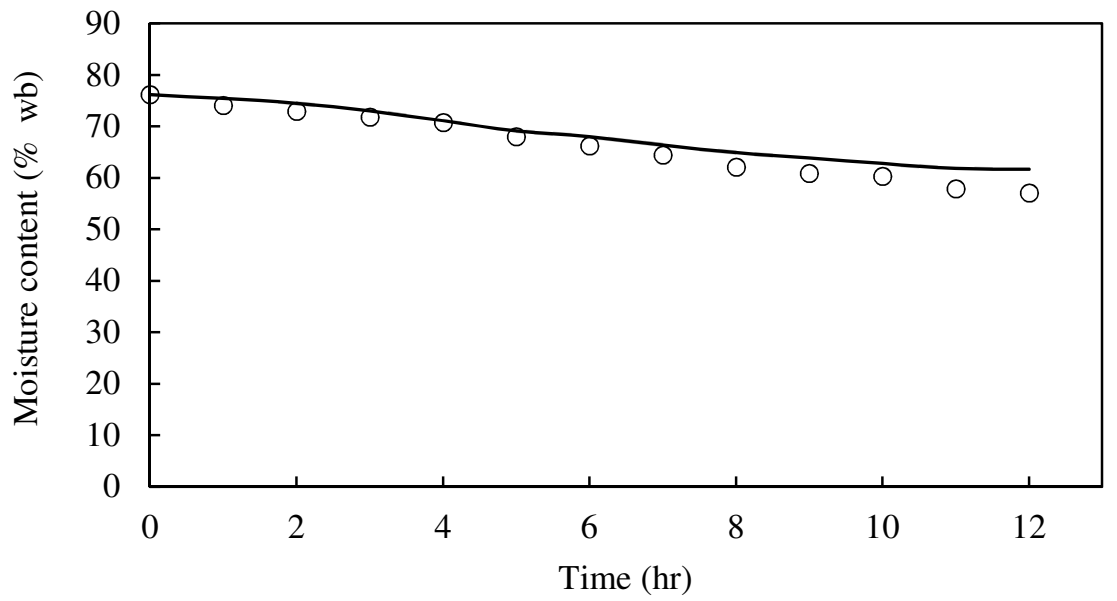

○ withered leaves moisture content $\quad$ model computed moisture content

Figure 6. Model computed moisture content and the withered leaves moisture content with time. 
Table 2. Standard error of estimations for the three trials.

\section{Trials}

\begin{tabular}{ll} 
Trial 1 & 5.05 \\
Trial 2 & 2.83 \\
Trial 3 & 4.04 \\
\hline
\end{tabular}

Standard error of estimation

(\% moisture content wet basis)

Table 2 illustrates that the standard error of estimation of the three experiments during the withering process. The standard error of estimation of the first trial was 5.05 while it was 2.83 and 4.04 in the second and third trials, respectively. The electrical energy consumption, specific electricity consumption, final moisture content and the duration of withering with the control system and without control system are listed in Table 3.

Table 3. Energy consumption, removal of moisture, initial and final moisture content with and without control system.

\begin{tabular}{|c|c|c|c|c|c|c|c|}
\hline \multicolumn{2}{|c|}{ Experiments } & $\begin{array}{c}\text { Initial } \\
\text { MC } \\
(\% \\
\text { w.b. })\end{array}$ & $\begin{array}{c}\text { Final } \\
\text { MC } \\
(\% \\
\text { w.b. })\end{array}$ & $\begin{array}{c}\text { Withering } \\
\text { hours } \\
\text { (hr) }\end{array}$ & $\begin{array}{c}\text { Energy } \\
(\mathbf{k W h})\end{array}$ & $\begin{array}{c}\text { Removal of } \\
\text { Moisture } \\
\text { kg.kW-1 } \mathbf{h}^{-1}\end{array}$ & $\begin{array}{c}\text { Specific } \\
\text { Electricity } \\
\text { consumption } \\
\left(\mathbf{k W h . k g}{ }^{-1}\right. \\
\text { made tea) }\end{array}$ \\
\hline \multirow{3}{*}{$\begin{array}{l}\text { with } \\
\text { control } \\
\text { system }\end{array}$} & $\begin{array}{l}\text { Trial } \\
\text { I }\end{array}$ & 78 & 57.5 & $11: 45$ & 36.25 & 11.97 & 0.18 \\
\hline & $\begin{array}{l}\text { Trial } \\
\text { II }\end{array}$ & 76.2 & 57.6 & $11: 00$ & 38.76 & 10.18 & 0.18 \\
\hline & $\begin{array}{l}\text { Trial } \\
\text { III }\end{array}$ & 75.2 & 56.6 & $12: 00$ & 38.57 & 9.9 & 0.17 \\
\hline \multirow{3}{*}{$\begin{array}{l}\text { With } \\
\text { out } \\
\text { control } \\
\text { system }\end{array}$} & $\begin{array}{l}\text { Trial } \\
\text { I }\end{array}$ & 77.2 & 57.1 & $16: 00$ & 55.92 & 7.55 & 0.27 \\
\hline & $\begin{array}{l}\text { Trial } \\
\text { II }\end{array}$ & 79.3 & 56.3 & $16: 40$ & 64.34 & 8.48 & 0.35 \\
\hline & $\begin{array}{l}\text { Trial } \\
\text { III } \\
\end{array}$ & 78.6 & 57 & $15: 45$ & 66.24 & 6.82 & 0.34 \\
\hline
\end{tabular}

Table 3 shows that the electrical energy consumption changed in the range of $36 \mathrm{kWh}$ to $39 \mathrm{kWh}$ with the control system while it was in the range of $55 \mathrm{kWh}$ to $67 \mathrm{kWh}$ without the control system. Electricity consumption to produce one $\mathrm{kg}$ of made tea was 0.17 to $0.18 \mathrm{kWh}$ with the control system while it was 0.27 to $0.35 \mathrm{kWh}$ without control system. De Silva (1994) stated that the theoretical specific electrical power consumption is about $0.16 \mathrm{kWh} \mathrm{kg}^{-1}$ while the actual consumption is about $0.46 \mathrm{kWh} \cdot \mathrm{kg}^{-1}$. Therefore, the results show controlling of withering parameters leads to a better energy saving. The rate of moisture removal was 9.9 to 
$11.97 \mathrm{~kg}$ moisture for one unit of energy ( $\mathrm{kWh}$ ) with control system and it was 6.82 to $8.48 \mathrm{~kg}$ moisture for one unit of energy $(\mathrm{kWh})$ in withering process without control system with the standard deviation 0.7562 and $0.461\left(\mathrm{~kg}\right.$ moisture. $\left.\mathrm{kW}^{-1} \mathrm{~h}^{-1}\right)$ respectively.

The quality parameters (Thearubigins, Theaflavins, color, percentage brightness, and ratio of Thearubigins to Theaflavin) of the made tea samples produced with control system and without control withering system were measured in trials are presented in Table 4.

Table 4. Quality parameters of the made tea, produced with control system and without control system.

\begin{tabular}{cccccc}
\hline $\begin{array}{c}\text { Quality } \\
\text { parameters }\end{array}$ & TF & TR & Color & Br (\%) & TR/TF \\
\hline $\begin{array}{c}\text { With control } \\
\text { withering system }\end{array}$ & 0.952 & 14.8 & 4.98 & 17.82 & 15.5 \\
& 0.936 & 13.7 & 3.84 & 23.29 & 14.7 \\
$\begin{array}{c}\text { Without control } \\
\text { withering system }\end{array}$ & 0.839 & 13.7 & 3.9 & 21.2 & 16.3 \\
\hline
\end{tabular}

$\mathrm{TR}=$ Thearubigins, $\mathrm{TF}=$ Theaflavins and $\mathrm{Br}=$ brightness

The ratio of Thearubigins to Theaflavin was very much closer in the treatment samples and the control samples. It was reported that TF to TR ratio of 1:10 gives an idealized liquor color and brightness (Robert and Smith, 1963). It was also seen that no significant difference between other parameters such as Thearubigins, Theaflavin, color, and percentage brightness in these experiments.

\section{CONCLUSION}

The results show that the electrical energy consumption for withering $900 \mathrm{~kg}$ of green leaves was $36 \mathrm{kWh}$ to $39 \mathrm{kWh}$ with the control system and it was in the range of $55 \mathrm{kWh}$ to $67 \mathrm{kWh}$ in the withering process without control system. Therefore, $39 \%$ of electrical energy was achieved by introducing the control system as against the withering process without control system. Also, the results revealed that the quality of made tea produced with the control system was slightly better than the tea produced without the control system. Therefore, it could be concluded that the developed control system for trough withering conserves electrical energy as well as quality against the withering process without control system.

\section{REFERENCES}

Botheju, W.S. Amarathunga, K.S.P. \& Abeysinghe, I.S.B. (2010). Modelling trough withering system to predict the moisture content of tea leaves at real time using ID - Heat \& mass transfer finite difference model. S.L.J Tea Sci. 75, 27-45. 
Daranagama, U. Nadeera, H.A.W. Kithsiri, B.A.G. Weerakkody, D. Galahitiyawa, G. and Mohamed, M.T.Z. (2002). Conservation of electrical energy in trough withering. S.L.J Tea Sci. 67(1\&2), 37-46.

De Silva, W.C.A. (1994). Status review of energy utilization by the tea industry in Sri Lanka. S.L.J Tea Sci. 63(2), 46-58pp.

Haskoning, (1989). Royal Dutch consulting engineers and architects. Energy conservation in the tea industry of Sri Lanka, pp. 206.

ISO 1568 (1980). Tea - Determination of loss in mass at $103^{\circ} \mathrm{C}$. International Standard Organization Second Edition, Switzerland. pp. 1573-1980.

Keegal, E.L. (1965). Withering. Tea Manufacture in Ceylon. pp. 28-41. In: E. L Keegal (Ed.) Monographs on tea production in Ceylon. $2^{\text {nd }}$ Edition, Tea Research Institute of Sri Lanka.

Millin, D. J. (1987). Effect of processing on composition and quality. A withering. Factors affecting the quality of tea, Academic Press, London, 4, pp 135.

Roberts, G.R. (2008). Principles of Tea Manufacture. Handbook on Tea. Tea Research Institute of Sri Lanka.

Samaraweera, D.S.A. (1986). Technology of tea processing. pp. 158-207. In: Sivapalan, P., Kulasegaram, S. and Kathiravetpillai, A. (Eds.) Handbook on Tea. Tea Research Institute of Sri Lanka. 